\title{
Modeling of UTSG in the Pressurized Water Reactor Using Accurate Formulae of Thermodynamic Properties
}

\author{
Amir M. Alramady¹, Sheikha Al-Sharif ${ }^{2}$, Sherif S. Nafee ${ }^{2,3}$ \\ ${ }^{1}$ Deanship of Graduate Studies, King Abdulaziz University, Jeddah, Kingdom of Saudi Arabia \\ ${ }^{2}$ Physics Department, Faculty of Science, King Abdulaziz University, Jeddah, Kingdom of Saudi Arabia \\ ${ }^{3}$ Physics Department, Faculty of Science, Alexandria University, Alexandria, Egypt \\ Email: ameerkamel@hotmail.com,snafee@kau.edu.sa
}

How to cite this paper: Alramady, A.M., Al-Sharif, S. and Nafee, S.S. (2021) Modeling of UTSG in the Pressurized Water Reactor Using Accurate Formulae of Thermodynamic Properties. Journal of Applied Mathematics and Physics, 9, 947-967.

https://doi.org/10.4236/jamp.2021.95065

Received: April 8, 2021

Accepted: May 16, 2021

Published: May 19, 2021

Copyright $\odot 2021$ by author(s) and Scientific Research Publishing Inc. This work is licensed under the Creative Commons Attribution International License (CC BY 4.0).

http://creativecommons.org/licenses/by/4.0/

\begin{abstract}
In nuclear power plants, steam generators are important parts. This paper introduces a U-tube steam generator (UTSG) model implemented completely using MATLAB environment. The UTSG consists of four regions: upward and downward primary regions, upward and downward metal tube regions, and secondary regions, which contain heat transfer region, steam separation region, and subcooled water region. Governing equations are derived by applying energy and mass conservation equations in all regions. Accurate functions that describe the relationships between thermodynamic properties of the saturated steam are introduced instead of interpolation method that is widely used. Steady state and one transient case are presented as well.
\end{abstract}

\section{Keywords}

UTSG Modeling, Steam Tables, Thermodynamic Properties

\section{Introduction}

Steam generators (SGs) of the vertical recirculating type (UTSG) are the dominant types that are used in the pressurized water reactors (PWRs). SGs are heat exchangers containing thousands of tubes to transfer heat from the primary coolant which represents the hot side to the secondary coolant which represents the cold side to produce steam, that produce electricity by powering turbine generators. A large number of nuclear power plants (NPPs) have from 2 to 6 SGs; however some have up to 12 SGs [1]. In nuclear power plants overall the world, there are around 1300 SGs being in service. 
Water/Steam thermodynamic properties are required in equation derivation of SG models. These properties are available in the form of plots or tables. Extracting data directly from these plots or tables is not suitable for dynamic modeling. Therefore, most of the researchers expressed them in linear mathematical forms, which can be effective for simulation purposes. In UTSG mathematical models, the relations of the specific volumes/densities of the vapor and liquid, and their specific enthalpy of the vapor and liquid and saturated temperature that depend on the saturation pressure $\left(P_{\text {sat }}\right)$ are required. Typically, such relationships can be found for pressure intervals in thermodynamic properties tables [2]. Many of these models develop approximating formulae using an interpolation method. In addition, the relationships of the derivatives of these parameters are also needed [3]. That is the reason that most of the models use linear approximating formulae.

Recently, many researchers reported the modeling of the UTSG using different platforms. For example, the derivation of the UTSG model was done using MATLAB as a part of a complete power plant simulator [4]. They used steam tables from Ref. [5] to get water/steam properties using interpolation functions programmed in $\mathrm{C}++$ and FORTRAN languages. Reference [6] used an external software package to calculate the physical parameters of water and vapor. Then, a dynamic model for steady-state and transient responses was programmed on a personal computer using MATLAB/SIMULINK. While in Ref. [7], a dynamic model of AP1000 steam generator introduced using the following assumption: linear approximate profiles for volume weighted specific volume and specific enthalpy are used in secondary side tube bundle region. Other researchers reported the using of MATLAB to model Steam Generators as in [8] [9] [10] [11] [12] to do the same for calculating water/steam properties.

In the present work, a mathematical model for the UTSG is introduced using a home-made computer model written fully using MATLAB programming environment. It is well known that if there are many measurement data, MATRIXx environment provides a quick solution to the least square's problems, so matrix calculations can be performed easily using commercial software packages such as MATHCAD and MATLAB [1]. MATLAB is widely used in modeling of steam generators because of its interactive programmable matrix calculator with graphics capabilities [13].

The Steam Generator is divided into four regions according to Ali's second intermediate model (model C) for the UTSG, which is utilized in this work using a MATLAB Program [14]. The regions are: upward and downward primary regions which represent primary water pumped from the reactor cooling pump going up then down inside thousands of inverted $U$ tubes, and during this movement heat transferred through upward and downward metal tube regions. Finally, the heat is transferred to the secondary regions where the cold feed water uses this heat to generate steam; then steam is separated during its way to turbine. Governing equations are derived by applying energy, mass, and momentum conservation equations on all regions. 
The most popular design for steam generators is UTSG [1]. Figure 1 represents a schematic diagram of an inverted $U$-shaped vertical steam generator, in which all parts of the steam generator are contained within a cylindrical vessel and the pre-cooling water coming from the reactor core enters the inlet at a pressure of about $15 \mathrm{MPa}$ facing upward at the inverted $\mathrm{U}$. This flowing water transfers the heat to the secondary water in the steam generator through the pipe walls without mixing. The primary cooling water enters the steam generator at approximately $583-600 \mathrm{~K}$ and exits at $530-560 \mathrm{~K}$. Also, the steam mass ratio varies from $17 \%-33 \%$. The higher this percentage, the higher the efficiency of the steam generator and the better for the turbine because this wet steam cannot be sent to the high -pressure turbine, which increases the need for high techniques to remove the liquid from the steam as much as possible [15].

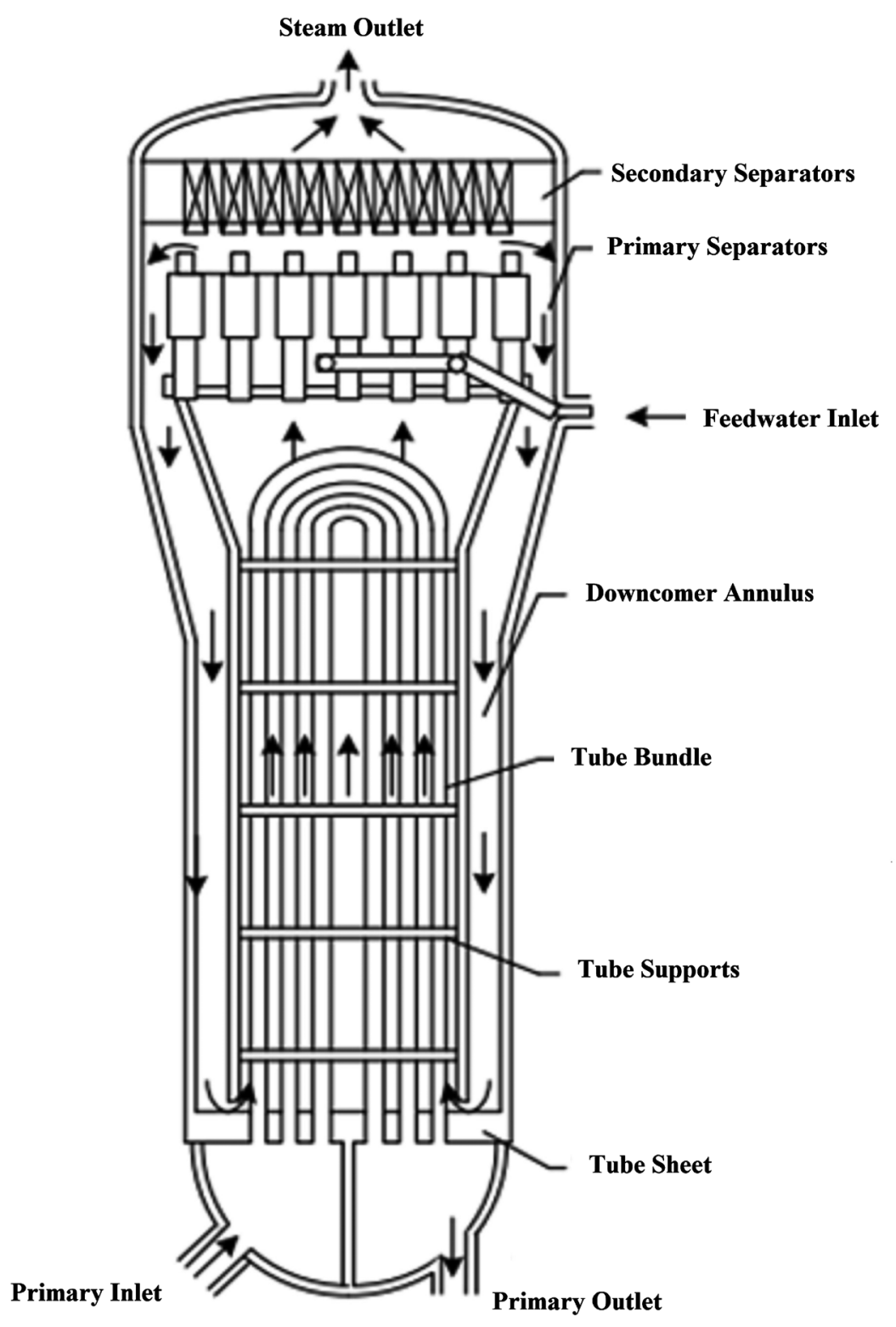

Figure 1. U-tube steam generators for nuclear power plant [1]. 


\section{The UTSG Model Equations}

\subsection{Assumptions}

The first step in the UTSG modeling is to make appropriate assumptions. These assumptions are introduced to smoothing calculations and minimizing the complexity. The basic assumptions on which our model is constructed are:

1) One dimensional flow for primary and secondary cooling water.

2) Primary flow $\left(W_{p i}\right)$ is constant.

3) Steam exit flow $\left(W_{s o}\right)$ is proportion to saturated pressure $\left(P_{\text {sat }}\right)$.

4) Thermal conductivity of the inverted metal tube is constant.

5) Heat transfer coefficients are assumed to be constant during transients.

6) Heat transfer between the tube bundle area and the downcomer is neglected.

7) Flow of exit Steam $\left(W_{s o}\right)=$ flow of feedwater $\left(W_{f i}\right)$.

\subsection{UTSG Parameters and Design State Values}

The current mathematical model of UTSG is based on the geometrical parameters and the numerical constants for the four regions listed in Table 1 and Table 2, respectively [4]. In addition, Table 3 shows symbols and units of the variables used in the thermodynamic equations in the current model.

Table 1. Parameters of UTSG.

\begin{tabular}{|c|c|c|}
\hline Symbol & Description & Value and Units \\
\hline$A_{d}$ & Area of the coolant in the accumulation tank & $3 \mathrm{~m}^{2}$ \\
\hline$A_{d W}$ & Area of coolant in recirculation region & $10.3 \mathrm{~m}^{2}$ \\
\hline$C_{m}$ & Specific heat capacity of metal tubes & $460 \mathrm{~J} /\left(\mathrm{kg}^{\circ} \mathrm{C}\right)$ \\
\hline$C_{s}$ & Conversion factor between Wso and Psat & $80 \mathrm{~kg} /(\mathrm{s} \mathrm{MPa})$ \\
\hline$K$ & thermal conductivity of metal tube & $55.0012 \mathrm{Jsm}^{\circ} \mathrm{C}$ \\
\hline$L$ & height of U-tube & $10.83 \mathrm{~m}$ \\
\hline$L_{d}$ & Height of accumulation tank & $10.83 \mathrm{~m}$ \\
\hline$L_{s b}$ & height of liquid & $1.057 \mathrm{~m}$ \\
\hline$M_{3}$ & Mass of half of total metal tube upward & $25,600 \mathrm{~kg}$ \\
\hline$M_{4}$ & Mass of half of total metal tube downward & $25,600 \mathrm{~kg}$ \\
\hline$N$ & total number of U-tubes & 3388 \\
\hline$R_{\text {avg }}$ & $\left(R_{\text {in }}+R_{\text {out }}\right) / 2$ & $10.357 \mathrm{~cm}$ \\
\hline$R_{\text {in }}$ & inner radius of $\mathrm{U}$-Tube & $9.75 \mathrm{~cm}$ \\
\hline$R_{\text {out }}$ & outer radius of $\mathrm{U}$-Tube & $11 \mathrm{~cm}$ \\
\hline$T_{f i}$ & Temperature of inlet feed water & $223^{\circ} \mathrm{C}$ \\
\hline$T_{p}$ & Temperature of primary water & $312^{\circ} \mathrm{C}$ \\
\hline$U_{m s}$ & heat transfer coefficient between the metal tubes and the secondary water & $\mathrm{J} /\left(\mathrm{s} \mathrm{m}^{2 \circ} \mathrm{C}\right)$ \\
\hline$V_{d r}$ & Volume of drum & $124.5 \mathrm{~m}^{3}$ \\
\hline$V_{r}$ & Internal volume of Liquid/Vapor separator & $13.3 \mathrm{~m}^{3}$ \\
\hline$V_{s}$ & volume of the secondary coolant in the effective heat exchange region & $94.4 \mathrm{~m}^{3}$ \\
\hline$W_{p}$ & Flow rate of primary water & $4950 \mathrm{~kg} / \mathrm{s}$ \\
\hline$\rho_{d}$ & metal tube density & 8490 \\
\hline$\rho_{m}$ & Density of metal tube & $8500 \mathrm{~kg} / \mathrm{m}^{3}$ \\
\hline
\end{tabular}


Table 2. Design steady state values of UTSG.

\begin{tabular}{clc}
\hline Symbol & \multicolumn{1}{c}{ Description } & Value and Units \\
\hline$T_{1}$ & Temperature of primary coolant flowing upward & $576 \mathrm{~K}$ \\
$T_{2}$ & Temperature of primary coolant flowing downward & $569 \mathrm{~K}$ \\
$T_{3}$ & Temperature of metal tube of coolant flowing upward & $571 \mathrm{~K}$ \\
$T_{4}$ & Temperature of metal tube of coolant flowing downward & $565 \mathrm{~K}$ \\
$T_{5}$ & Temperature of recirculated water & $535 \mathrm{~K}$ \\
$T_{6}$ & Temperature of water in the mixing region & $535 \mathrm{~K}$ \\
$L_{s}$ & Level of water of mixing region of secondary coolant & $3.2 \mathrm{~m}$ \\
$x_{b}$ & Quality of coolant at the end of the boiling region & 0.233 \\
$P_{s a t}$ & Saturation Pressure of secondary water in boiling region & $5.9 \mathrm{MPa}$ \\
\hline
\end{tabular}

Table 3. Symbols and units of the variables used in the current model.

\begin{tabular}{|c|c|c|}
\hline Symbol & Description & Units \\
\hline$A_{m s}$ & Surface area in contact between secondary water and metal tubes & $\mathrm{m}^{2}$ \\
\hline$A_{p m}$ & Surface area in contact between and metal tubes and primary coolant & $\mathrm{m}^{2}$ \\
\hline$C_{p}$ & specific heat of subcooled water & $\mathrm{J} /\left(\mathrm{kg}^{\circ} \mathrm{C}\right)$ \\
\hline$h_{f}$ & saturated water specific enthalpy & $\mathrm{kJ} / \mathrm{kg}$ \\
\hline$h_{f g}$ & $H_{f}-h_{g}$ & $\mathrm{~kJ} / \mathrm{kg}$ \\
\hline$h_{g}$ & saturated vapor specific enthalpy & $\mathrm{kJ} / \mathrm{kg}$ \\
\hline$h_{s}$ & average enthalpy of secondary water & $\mathrm{kJ} / \mathrm{kg}$ \\
\hline$L_{b}$ & height of boiling column & $\mathrm{m}$ \\
\hline$M_{d}$ & Mass of water in annular tank & $\mathrm{kg}$ \\
\hline$M_{d w}$ & mass of drum water & $\mathrm{kg}$ \\
\hline$M_{p}$ & Mass of half of the primary water & $\mathrm{kg}$ \\
\hline$M_{s}$ & mass of secondary coolant & $\mathrm{kg}$ \\
\hline$\dot{Q}_{m s 1}$ & upward metal tube to secondary coolant heat transfer rate & $\mathrm{J} / \mathrm{s}$ \\
\hline$\dot{Q}_{m s 2}$ & downward metal tube to secondary coolant heat transfer rate & $\mathrm{J} / \mathrm{s}$ \\
\hline$T_{s}$ & Average bulk mean temperature in the secondary lump & ${ }^{\circ} \mathrm{C}$ \\
\hline$T_{\text {sat }}$ & saturation temperature & ${ }^{\circ} \mathrm{C}$ \\
\hline$U_{m s}$ & Coefficient of heat transfer between the secondary coolant and metal tubes & $\mathrm{J} /\left(\mathrm{s} \mathrm{m}^{2 \circ} \mathrm{C}\right)$ \\
\hline$U_{p m}$ & Coefficient of heat transfer between the primary coolant and metal tubes & $\mathrm{J} /\left(\mathrm{s} \mathrm{m}^{2 \circ} \mathrm{C}\right)$ \\
\hline$W_{1}$ & mass flow rate of fluid from the downcomer to the riser & $\mathrm{Kg} / \mathrm{s}$ \\
\hline$W_{2}$ & Mass flow rate of outlet secondary water & $\mathrm{Kg} / \mathrm{s}$ \\
\hline$W_{3}$ & mass flow rate of secondary coolant leaving separator & $\mathrm{kg} / \mathrm{s}$ \\
\hline$W_{f i}$ & Flow rate of feed water & $\mathrm{kg} / \mathrm{s}$ \\
\hline$W_{s o}$ & Flow rate of saturated steam & $\mathrm{kg} / \mathrm{s}$ \\
\hline$\rho_{\mathrm{f}}$ & saturated liquid density & $\mathrm{kg} / \mathrm{m}^{3}$ \\
\hline$\rho_{\mathrm{g}}$ & saturated vapor density & $\mathrm{kg} / \mathrm{m}^{3}$ \\
\hline$v_{f}$ & saturated liquid specific volume & $\mathrm{m}^{3} / \mathrm{kg}$ \\
\hline$v_{f g}$ & $v_{f}-v_{g}$ & $\mathrm{~m}^{3} / \mathrm{kg}$ \\
\hline$v_{g}$ & saturated vapor specific volume & $\mathrm{m}^{3} / \mathrm{kg}$ \\
\hline
\end{tabular}




\subsection{State Equations for UTSG Model}

Nodalization scheme of the UTSG model is shown in Figure 2. The model governing the equations is derived by applying energy, mass, and momentum conservation equations.

Primary coolant equations derivation is done by applying the energy conservation equation to both PRIMARY_UP and PRIMARY_DOWN, which represent the moving of primary coolant up and down inside the inverted U-tube respectively (Figure 2).

$$
\begin{gathered}
\frac{\mathrm{d}}{\mathrm{d} t}\left(M_{p} * C_{p} * T_{1}\right)=W_{p i} * C_{p}\left(T_{p}-T_{1}\right)-U_{p m} * A_{p m} *\left(T_{1}-T_{3}\right) \\
M_{p} * C_{p} * \frac{\mathrm{d} T_{1}}{\mathrm{~d} t}=W_{p i} * C_{p} * T_{p}-W_{p i} * C_{p} * T_{1}-U_{p m} * A_{p m} * T_{1}+U_{p m} * A_{p m} * T_{3} \\
U_{p m}=\frac{1}{\frac{1}{h_{i}}+\frac{R_{i n}}{k} * \log \left(\frac{R_{\text {avg }}}{R_{i n}}\right)}
\end{gathered}
$$

so

$$
\frac{\mathrm{d} T_{1}}{\mathrm{~d} t}=\left(\frac{-W_{p i}}{M_{p}}-\frac{U_{p m} * A_{p m}}{M_{p} * C_{p}}\right) T_{1}+\left(\frac{U_{p m} * A_{p m}}{M_{p} * C_{p}}\right) T_{3}+\left(\frac{W_{p i}}{M_{p}}\right) T_{p i}
$$

In the same way, we have

$$
\frac{\mathrm{d} T_{2}}{\mathrm{~d} t}=\left(\frac{-W_{p i}}{M_{p}}-\frac{U_{p m} * A_{p m}}{M_{p} * C_{p}}\right) T_{2}+\left(\frac{U_{p m} * A_{p m}}{M_{p} * C_{p}}\right) T_{4}+\left(\frac{W_{p i}}{M_{p}}\right) T_{1}
$$

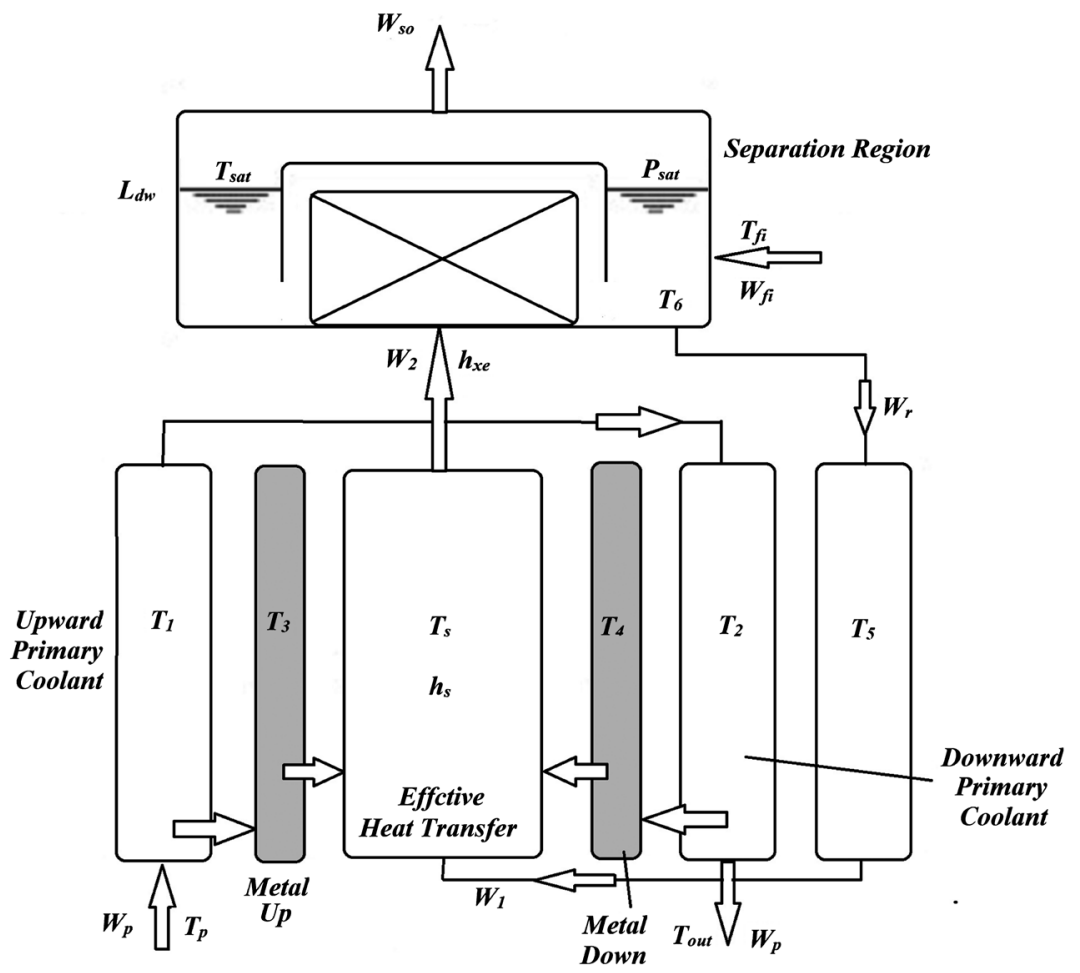

Figure 2. Schematic diagram of the UTSG. 
Also, U-Tube metal region equations derivation is done by applying the energy conservation equation on both METAL_UP and METAL_DOWN, which represent the inverted $U$-metal tube up flow and downflow respectively as shown in Figure 2.

$$
\begin{gathered}
\frac{\mathrm{d}}{\mathrm{d} t} M_{3} * C_{m} * T_{3}=U_{p m} * A_{p m} *\left(T_{1}-T_{3}\right)-U_{m s} * A_{m s} *\left(T_{3}-T_{s}\right) \\
U_{m s}=\frac{1}{\frac{1}{h_{d}}+\frac{R_{\text {out }}}{k} * \log \left(\frac{R_{\text {out }}}{R_{\text {avg }}}\right)} \\
\frac{\mathrm{d} T_{3}}{\mathrm{~d} t}=\left(\frac{-U_{p m} * A_{p m}-U_{m s} * A_{m s}}{M_{3} * C_{m}}\right) T_{3}+\left(\frac{U_{p m} * A_{p m}}{M_{3} * C_{m}}\right) T_{1}+\left(\frac{U_{m s} * A_{m s}}{M_{3} * C_{m}}\right) T_{s}
\end{gathered}
$$

In the same way, we have

$$
\frac{\mathrm{d} T_{4}}{\mathrm{~d} t}=\left(\frac{-U_{p m} * A_{p m}-U_{m s} * A_{m s}}{M_{4} * C_{m}}\right) T_{4}+\left(\frac{U_{p m} * A_{p m}}{M_{4} * C_{m}}\right) T_{2}+\left(\frac{U_{m s} * A_{m s}}{M_{4} * C_{m}}\right) T_{s}
$$

Secondary coolant region equations derivation is done applying energy and mass conservation equations on the three secondary coolant regions: Effective heat transfer region (EHT), upper tank region (ACCU_T), and Inlet annular tank region (IA_T) as shown in Figure 2.

EHT region of secondary cooling water is the area of heat accumulation in the metal tubes. Because of the heat build-up, the secondary cooling water is pushed up, and the energy conservation equation can be written as follows:

$$
\begin{gathered}
\frac{\mathrm{d}}{\mathrm{d} t}\left(h_{s} * M_{s}\right)=\dot{Q}_{m s 1}+\dot{Q}_{m s 2}+W_{1} * C_{p s} * T_{5}-W_{2} * h_{e} \\
V_{s} \frac{\mathrm{d}}{\mathrm{d} t}\left(\rho_{s} * h_{s}\right)= \\
U_{m s} * A_{m s} *\left(T_{3}-T_{s}\right)+U_{m s} * A_{m s} *\left(T_{4}-T_{s}\right) \\
+W_{1} * C_{p s} * T_{5}-W_{2} * h_{e}
\end{gathered}
$$

Now the following equations are deduced for the average thermodynamic properties of the secondary coolant in the effective heat exchange mass.

$$
\begin{gathered}
L=L_{s b}+L_{b} \\
T_{s}=\frac{T_{5}+T_{s a t}}{2} * \frac{L_{s b}}{L}+T_{s a t} * \frac{L_{b}}{L} \\
\rho_{s}=\frac{\rho_{d}+\rho_{f}}{2} * \frac{L_{s b}}{L}+\frac{L_{b}}{\left(v_{f}+\frac{x_{e}}{2} * v_{f g}\right) * L} \\
h_{s}=C_{p s} * \frac{T_{5}+T_{s a t}}{2} * \frac{L_{s b}}{L}+\left(h_{f}+\frac{x_{e}}{2} * h_{f g}\right) * \frac{L_{b}}{L} \\
h_{e}=h_{f}+x_{e} * h_{f g}
\end{gathered}
$$

The heat transfer in the ACCU_T zone is not carried out immediately when the secondary coolant meets the metal tubes. It is in this region specifically that the secondary cooling water is in the state of saturation, as a mixture of water 
and steam. And dryers are used to separate the steam from the water to allow the steam to flow into the turbine while the rest of the water is returned to the inlet ring tank to be mixed with the feed water. Now by applying the continuity equations only to the mixture of water vapor and mass of vapor respectively, and by applying both the continuity equations and the energy balance to the mass of water only:

$$
\begin{gathered}
\frac{\mathrm{d}\left(V_{r} * \rho_{r}\right)}{\mathrm{d} t}=W_{2}-W_{3} \\
\frac{\mathrm{d}\left(L_{d w} * A_{d w} * \rho_{f}\right)}{\mathrm{d} t}=W_{f i}+\left(1-x_{e}\right) * W_{3}-W_{1} \\
\frac{\mathrm{d}\left(M_{d w} * C_{p s} * T_{6}\right)}{\mathrm{d} t}=W_{f i} * M_{d w} * C_{p s} * T_{f i}+\left(1-x_{e}\right) * W_{3} * C_{p s} * T_{s a t} \\
-W_{1} * C_{p s} * T_{6} \\
\frac{\mathrm{d}\left(\left(V_{d r}-A_{d w} * L_{d w}\right) * \rho_{g}\right)}{\mathrm{d} t}=x_{e} * W_{3}-W_{s o}
\end{gathered}
$$

Subcooled water in IA_T region of UTSG is a mixture of both recycled water from the previous zone and the main feed water. By applying the energy balance:

$$
\frac{\mathrm{d}\left(M_{d} * C_{p s} * T_{5}\right)}{\mathrm{d} t}=W_{1} * C_{p s} * T_{6}-W_{1} * C_{p s} * T_{5}
$$

We can rewrite Equation (21) as:

$$
\frac{\mathrm{d} T_{5}}{\mathrm{~d} t}=\frac{W_{1}}{M_{d}} * T_{6}-\frac{W_{1}}{M_{d}} * T_{5}
$$

From Equations (18) and (19):

$$
\frac{\mathrm{d} T_{6}}{\mathrm{~d} t}=\left(\frac{W_{3}\left(x_{e}-1\right) * W_{1-W_{f i}}}{L_{d w} * A_{d w} * \rho_{f}}\right) T_{6}+\frac{W_{f i}}{L_{d w} * A_{d w} * \rho_{f}} * T_{f i}+\frac{\left(1-x_{e}\right) * W_{3}}{L_{d w} * A_{d w} * \rho_{f}} * T_{s a t}
$$

From Equation (20):

$$
\begin{aligned}
W_{3}= & \frac{1}{x_{e}} *\left\{\left(\left(V_{d r}-A_{d w} * L_{d w}\right) * \frac{\mathrm{d} \rho_{g}}{\mathrm{~d} P}+\frac{\rho_{g}}{\rho_{f}} * A_{d w} * L_{d w} * \frac{\mathrm{d} \rho_{f}}{\mathrm{~d} P}\right) /\left(1+\frac{\left(1-x_{e}\right)}{x_{e}} * \frac{\rho_{g}}{\rho_{f}}\right)\right. \\
& \left.* \frac{\mathrm{d} P_{s a t}}{\mathrm{~d} t}-\frac{\rho_{v}}{\rho_{L}} * \frac{\left(W_{f i}-W_{1}\right)}{G_{2}}+\frac{W_{s o}}{G_{2}} A_{g}\right\}
\end{aligned}
$$

From Equations (17) and (24):

$$
\begin{aligned}
W_{2}= & \left\{\frac{1}{x_{e}} * G_{6}-\frac{V_{r} *\left(\frac{\mathrm{d} v_{f}}{\mathrm{~d} P}+x_{e} * \frac{\mathrm{d} v_{f g}}{\mathrm{~d} P}\right)}{\left(v_{f}+x_{e} * v_{f g}\right)^{2}}\right\} * \frac{\mathrm{d} P_{s a t}}{\mathrm{~d} t}-\left\{\frac{V_{r} * v_{f g}}{\left(v_{f}+x_{e} * v_{f g}\right)^{2}}\right\} * \frac{\mathrm{d} x_{e}}{\mathrm{~d} t} \\
& -\frac{1}{x_{e}} * \frac{\rho_{g}}{\rho_{f}} * \frac{W_{f i}-W_{1}}{\left(1+\frac{1-x_{e}}{x_{e}} * \frac{\rho_{g}}{\rho_{f}}\right)}+\frac{1}{x_{e}} * \frac{W_{s o}}{\left(1+\frac{1-x_{e}}{x_{e}} * \frac{\rho_{g}}{\rho_{f}}\right)}
\end{aligned}
$$


From Equation (18):

$$
\frac{\mathrm{d} L_{d w}}{\mathrm{~d} t}=\left(\frac{-1}{\rho_{f}} * \frac{\mathrm{d} \rho_{f}}{\mathrm{~d} P} * \frac{\mathrm{d} P_{s a t}}{\mathrm{~d} t}\right) * L_{d w}+\frac{1}{\rho_{f} * A_{d w}} *\left(W_{f i}+\left(1-x_{e}\right) * W_{3}-W_{1}\right)
$$

From Equations (10), (12), (24), (25), and (26), the state equations of both $P_{\text {sat }}$ and $x_{e}$ can be written as:

$$
\begin{aligned}
& \left.\frac{\mathrm{d} x_{e}}{\mathrm{~d} t}=\frac{\left(V_{s} * G_{5}+\left(\frac{1}{x_{e}} * G_{6}-\frac{V_{r} *\left(\frac{\mathrm{d} v_{f}}{\mathrm{~d} P}+x_{e} * \frac{\mathrm{d} v_{f g}}{\mathrm{~d} P}\right)}{\left(v_{f}+x_{e} * v_{f g}\right)^{2}}\right)\right) * U_{m s} * A_{m s}}{G_{1}}\right) \\
& +\left(W_{1} * C_{p s}+V_{s} * \rho_{s} * \frac{C_{p s} * L_{s b}}{2 * L} * \frac{W_{1}}{M_{d}}-U_{m s} * A_{m s} * \frac{L_{s b}}{L}\right) * T_{6} \\
& +\left(\frac{C_{p s} * L_{s b}}{\left.2 * \frac{W_{1}}{M_{d}}-U_{m s} * A_{m s} * \frac{L_{s b}}{L}\right) * G_{7}}\right. \\
& \left.G_{1}\right) * T_{5}+G_{8}
\end{aligned}
$$

and

$$
\begin{aligned}
& \frac{\mathrm{d} P_{s a t}}{\mathrm{~d} t}=\left(V_{s} *\left(\frac{L_{b}}{L} * \frac{\frac{v_{f g}}{2}}{\left(v_{f}+\frac{x_{e}}{2} * v_{f g}\right)^{2}}\right)\right) * \frac{U_{m s} * A_{m s}}{G_{1}} *\left(T_{3}+T_{4}\right) \\
& -\left(\frac{\left(V_{s} * \frac{L_{b}}{2 L} * v_{f g} /\left(v_{f}+\frac{x_{e}}{2} * v_{f g}\right)^{2}+G_{2}\right) * V_{s} * \rho_{s} *\left(C_{p s} * L_{s b}\right) * W_{1}}{2 * L * M_{d} * G_{1}}\right) * T_{6} \\
& +G_{3} * T_{5}+G_{4}
\end{aligned}
$$

where

$$
\begin{aligned}
& G_{1}=V_{s} *\left\{\frac{L_{s b}}{2 * L} * \frac{\mathrm{d} \rho_{f}}{\mathrm{~d} P}-\frac{L_{b}}{L} * \frac{\left(\frac{\mathrm{d} v_{f}}{\mathrm{~d} P}+\frac{x_{e}}{2} * \frac{\mathrm{d} v_{f g}}{\mathrm{~d} P}\right)}{\left(v_{f}+\frac{x_{e}}{2} * v_{f g}\right)^{2}}\right\} \\
& +\left\{\frac{1}{x_{e}} * G_{6}-\frac{V_{r} *\left(\frac{\mathrm{d} v_{f}}{\mathrm{~d} P}+x_{e} * \frac{\mathrm{d} v_{f g}}{\mathrm{~d} P}\right)}{\left(v_{f}+x_{e} * v_{f g}\right)^{2}}\right\} * V_{s} \\
& *\left(\rho_{s} *\left(\frac{L_{b}}{2 * L} * h_{f g}\right)-h_{s} *\left(\frac{L_{b}}{L} * \frac{\frac{v_{f g}}{2}}{\left(v_{f}+\frac{x_{e}}{2} * v_{f g}\right)^{2}}\right)\right)
\end{aligned}
$$




$$
\begin{aligned}
& -h_{e} *\left(\frac{V_{r} * v_{f g}}{\left(v_{f}+x_{e} * v_{f g}\right)^{2}}\right)+\left\{V_{s} *\left(\frac{L_{b}}{L} * \frac{\frac{v_{f g}}{2}}{\left(v_{f}+\frac{x_{e}}{2} * v_{f g}\right)^{2}}\right)+\left(\frac{V_{r} * v_{f g}}{\left(v_{f}+x_{e} * v_{f g}\right)^{2}}\right)\right\} \\
& *\left\{V_{s} *\left(\rho_{s} * G_{4}+h_{s} * G_{5}\right)+h_{e} *\left(\frac{1}{x_{e}} * G_{6}-\frac{V_{r} *\left(\frac{\mathrm{d} v_{f}}{\mathrm{~d} P}+x_{e} * \frac{\mathrm{d} v_{f g}}{\mathrm{~d} P}\right)}{\left(v_{f}+x_{e} * v_{f g}\right)^{2}}\right)\right\} \\
& G_{2}=\left(\frac{h_{e}}{x_{e}} * \frac{\rho_{g}}{\rho_{f}} * \frac{W_{f i}-W_{1}}{1+\frac{1-x_{e}}{x_{e}} * \frac{\rho_{g}}{\rho_{f}}}-2 * U_{m s} * A_{m s} *\left(\frac{L_{s b}}{2 * L}+\frac{L_{b}}{L}\right)\right) * T_{s a t} \\
& G_{3}=\frac{\left(V_{s} *\left(\frac{L_{b}}{L} * \frac{\frac{v_{f g}}{2}}{\left(v_{f}+\frac{x_{e}}{2} * v_{f g}\right)^{2}}\right)+\frac{V_{r} * v_{f g}}{\left(v_{f}+x_{e} * v_{f g}\right)^{2}}\right)}{G_{1}} \\
& *\left(W_{1} * C_{p s}+V_{s} * \rho_{s} *\left(\frac{C_{p s} * L_{s b}}{2 * L}\right) * \frac{W_{1}}{M_{d}}-U_{m s} * A_{m s} * \frac{L_{s b}}{L}\right) \\
& G_{4}=\frac{C_{p s} * L_{s b}}{2 * L} * \frac{\mathrm{d} T_{s a t}}{\mathrm{~d} P}+\frac{L_{b}}{L} *\left(\frac{\mathrm{d} h_{f}}{\mathrm{~d} P}+\frac{x_{e}}{2} * \frac{\mathrm{d} h_{f g}}{\mathrm{~d} P}\right) \\
& G_{5}=\frac{L_{s b}}{2 * L} * \frac{\mathrm{d} \rho_{f}}{\mathrm{~d} P}-\frac{L_{b}}{L} * \frac{\left(\frac{\mathrm{d} v_{f}}{\mathrm{~d} P}+\frac{x_{e}}{2} * \frac{\mathrm{d} v_{f g}}{\mathrm{~d} P}\right)}{\left(v_{f}+\frac{x_{e}}{2} * v_{f g}\right)^{2}} \\
& G_{6}=\left(\left(V_{d r}-A_{d w} * L_{d w}\right) * \frac{\mathrm{d} \rho_{g}}{\mathrm{~d} P}+\frac{\rho_{g}}{\rho_{f}} * A_{d w} * L_{d w} * \frac{\mathrm{d} \rho_{f}}{\mathrm{~d} P}\right) /\left(1+\frac{1-x_{e}}{x_{e}} * \frac{\rho_{g}}{\rho_{f}}\right) \\
& G_{7}=V_{s} * G_{5}+\frac{1}{x_{e}} * G_{6}-\frac{V_{r} *\left(\frac{\mathrm{d} v_{f}}{\mathrm{~d} P}+x_{e} * \frac{\mathrm{d} v_{f g}}{\mathrm{~d} P}\right)}{\left(v_{f}+x_{e} * v_{f g}\right)^{2}} \\
& V_{s} *\left(\rho_{s} *\left(\frac{C_{p s} * L_{s b}}{2 * L} * \frac{\mathrm{d} T_{s a t}}{\mathrm{~d} P}+\frac{L_{b}}{L} *\left(\frac{\mathrm{d} h_{f}}{\mathrm{~d} P}+\frac{x_{e}}{2} * \frac{\mathrm{d} h_{f g}}{\mathrm{~d} P}\right)\right)+h_{s} * G_{5}\right) \\
& G_{8}=-\frac{\left.+h_{e} *\left(\frac{1}{x_{e}} * G_{6}-\frac{V_{r} *\left(\frac{\mathrm{d} v_{f}}{\mathrm{~d} P}+x_{e} * \frac{\mathrm{d} v_{f g}}{\mathrm{~d} P}\right)}{\left(v_{f}+x_{e} * v_{f g}\right)^{2}}\right)\right)\left(\left(W_{1}+\frac{1}{x_{e}} * \frac{\rho_{g}}{\rho_{f}} * \frac{W_{f i}-W_{1}}{1+\frac{1-x_{e}}{x_{e}} * \frac{\rho_{g}}{\rho_{f}}}\right)-G_{2} * G_{7}\right.}{G_{1}} \\
& G_{8}=-\frac{\left.+h_{e} *\left(\frac{1}{x_{e}} * G_{6}-\frac{V_{r} *\left(\frac{\mathrm{d} v_{f}}{\mathrm{~d} P}+x_{e} * \frac{\mathrm{d} v_{f g}}{\mathrm{~d} P}\right)}{\left(v_{f}+x_{e} * v_{f g}\right)^{2}}\right)\right)\left(\left(W_{1}+\frac{1}{x_{e}} * \frac{\rho_{g}}{\rho_{f}} * \frac{W_{f i}-W_{1}}{1+\frac{1-x_{e}}{x_{e}} * \frac{\rho_{g}}{\rho_{f}}}\right)-G_{2} * G_{7}\right.}{G_{1}}
\end{aligned}
$$




$$
+\frac{\left(V_{s} *\left(\rho_{s} * G_{4}+h_{s} * G_{5}\right)+h_{e} *\left(\frac{1}{x_{e}} * G_{6}-\frac{V_{r} *\left(\frac{\mathrm{d} v_{f}}{\mathrm{~d} P}+x_{e} * \frac{\mathrm{d} v_{f g}}{\mathrm{~d} P}\right)}{\left(v_{f}+x_{e} * v_{f g}\right)^{2}}\right)\right)-h_{e} * G_{7}}{G_{1} * x_{e} *\left(1+\frac{1-x_{e}}{x_{e}} * \frac{\rho_{g}}{\rho_{f}}\right)} * W_{s o}
$$

\subsection{Accurate Formulae of Steam/Water Properties}

From Equations (15) to (36), we need to calculate the terms: $\rho_{V}, \rho_{L}, h_{V}, h_{L}$ and $T_{\text {sat }}$, which are functions of $P_{\text {sat }}$ Also we need their derivatives: $\frac{\mathrm{d} \rho_{V}}{\mathrm{~d} P_{\text {sat }}}, \frac{\mathrm{d} \rho_{L}}{\mathrm{~d} P_{\text {sat }}}$, $\frac{\mathrm{d} h_{V}}{\mathrm{~d} P_{\text {sat }}}, \frac{\mathrm{d} h_{L}}{\mathrm{~d} P_{\text {sat }}}$ and $\frac{\mathrm{d} T_{\text {sat }}}{\mathrm{d} P_{\text {sat }}}$.

We used MATLAB Curve Fitting Toolbox to provide an accurate functions or equations of steam/water properties taken from [16]. Also, the derivatives of functions are calculated easily. The MATLAB Curve Fitting Toolbox uses Linear and Nonlinear Regression to fit the data. It introduces extensive fitting capabilities. These functions are constant and can be used easily by itself or by their derivatives or integrals. These accurate functions introduced more accuracy for calculating of the thermodynamic properties of steam /water. Also, these functions give very fast computation, because steam properties are often called millions of times within the run of the model.

The formulae which are fitted are:

1) Vapor Saturated Density in terms of $P_{\text {sat }} \rho_{V}\left(P_{\text {sat }}\right)$ as shown in Figure 3 and Table 4.

2) Liquid Saturated Density in terms of $P_{\text {sap }} \rho_{L}\left(P_{\text {sat }}\right)$ as shown in Figure 4 and Table 5.

3) Vapor Saturated Enthalpy in terms of $P_{\text {sat }}, h_{V}\left(P_{\text {sat }}\right)$ as shown in Figure 5 and Table 6.

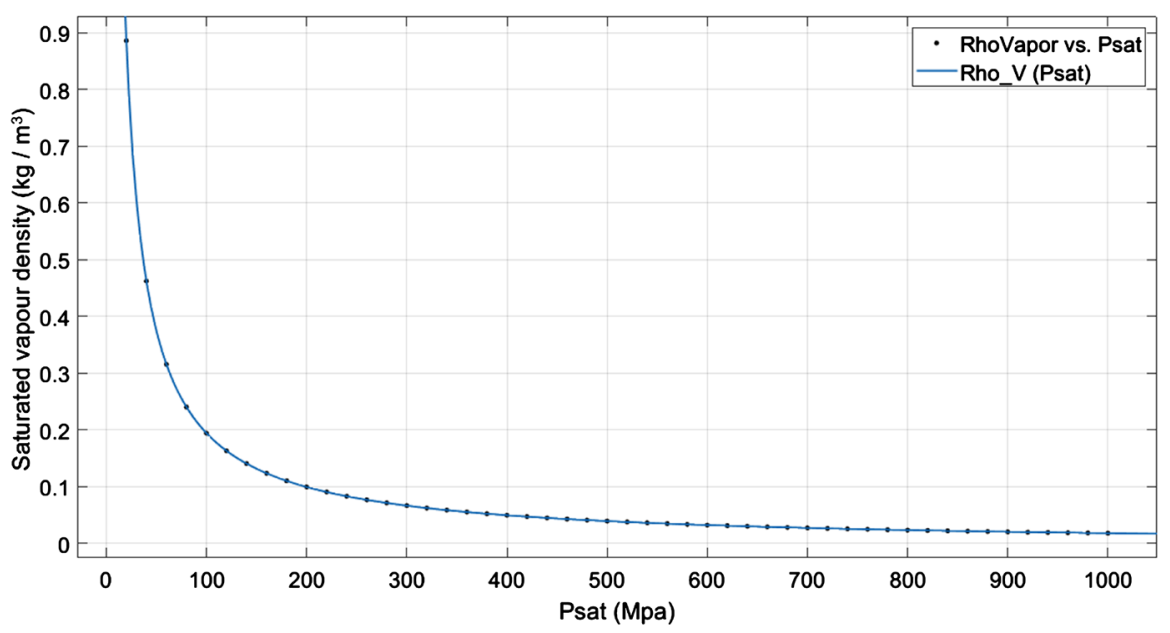

Figure 3. Fitting of saturated vapor density in terms of $P_{\text {sat }}$ 
Table 4. (a) General form of fitted curve of saturated vapor density in terms of $P_{\text {sap }}$ (b) Coefficients of the equation with confidence Interval. (c) Goodness of fit.

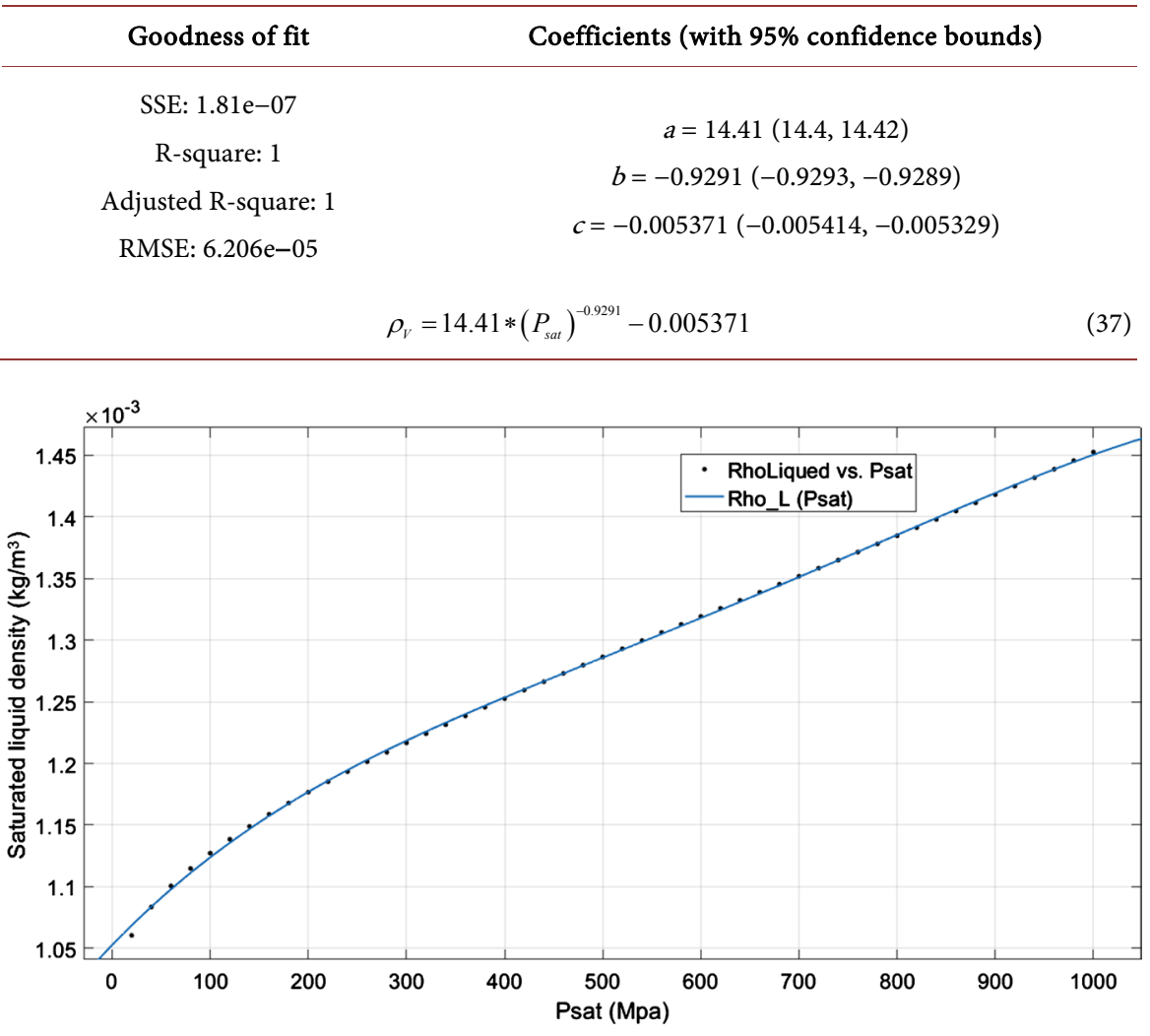

Figure 4. Fitting of saturated liquid density in terms of $P_{\text {sat }}$

Table 5. (a) General form of fitted curve of Saturated Liquid Density in terms of $P_{\text {sap }}$ (b) Coefficients of the equation with confidence Interval. (c) Goodness of fit.

\begin{tabular}{cc}
\hline Goodness of fit & Coefficients (with 95\% confidence bounds) \\
\hline SSE: $1.621 \mathrm{e}-10$ & $p_{1}=-5.342 \mathrm{e}-16(-6.484 \mathrm{e}-16,-4.2 \mathrm{e}-16)$ \\
R-square: 0.9997 & $p_{2}=1.383 \mathrm{e}-12(1.148 \mathrm{e}-12,1.617 \mathrm{e}-12)$ \\
Adjusted R-square: 0.9997 & $p_{3}=-1.276 \mathrm{e}-09(-1.437 \mathrm{e}-09,-1.116 \mathrm{e}-09)$ \\
RMSE: $1.898 \mathrm{e}-06$ & $p_{4}=8.258 \mathrm{e}-07(7.85 \mathrm{e}-07,8.665 \mathrm{e}-07)$ \\
& $p_{5}=0.001053(0.00105,0.001056)$ \\
$\rho_{L}=-5.342 \mathrm{e}-16 *\left(P_{\text {sat }}\right)^{4}+1.383 \mathrm{e}-12 *\left(P_{\text {sat }}\right)^{3}-1.276 \mathrm{e}-9 *\left(P_{\text {sat }}\right)^{2}-8.258 \mathrm{e}-7 * P_{\text {sat }}+0.001053 \quad$ (38)
\end{tabular}

4) Liquid Saturated Enthalpy in terms of $P_{\text {sat }} h_{V}\left(P_{\text {sat }}\right)$ as shown in Figure 6 and Table 7.

5) Saturated Temperature in terms of $P_{\text {sat }}, T_{\text {sat }}\left(P_{\text {sat }}\right)$ as shown in Figure 7 and Table 8.

It is clear that the results of the statistical data in Tables 4-8 show good compatibility according to four important statistical indicators; the first one is the (SSE), which represents the sum of squares due to the error and is considered a measure of the total deviation, the second one is R-Square, which is a measure of the variance of the data, the third is the Adjusted R-Square, which is closer to 


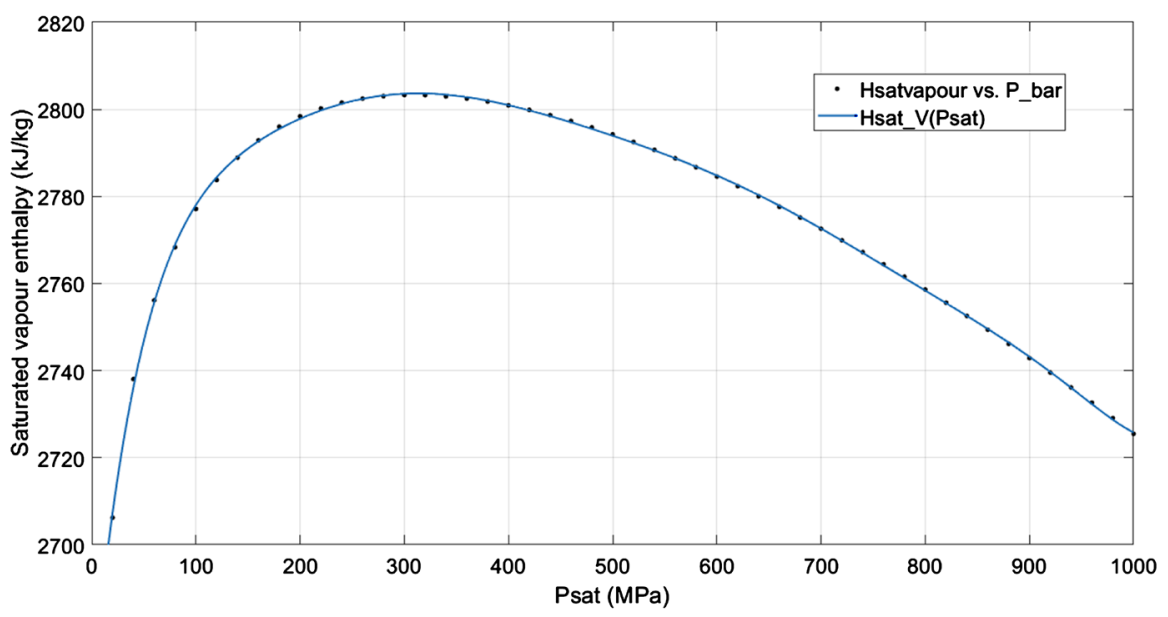

Figure 5. Fitting of saturated vapor enthalpy in terms of $P_{\text {sat }}$

Table 6. (a) General form of fitted curve of saturated vapor enthalpy in terms of $P_{\text {sap }}$ (b) Coefficients of the equation with confidence interval. (c) Goodness of fit.

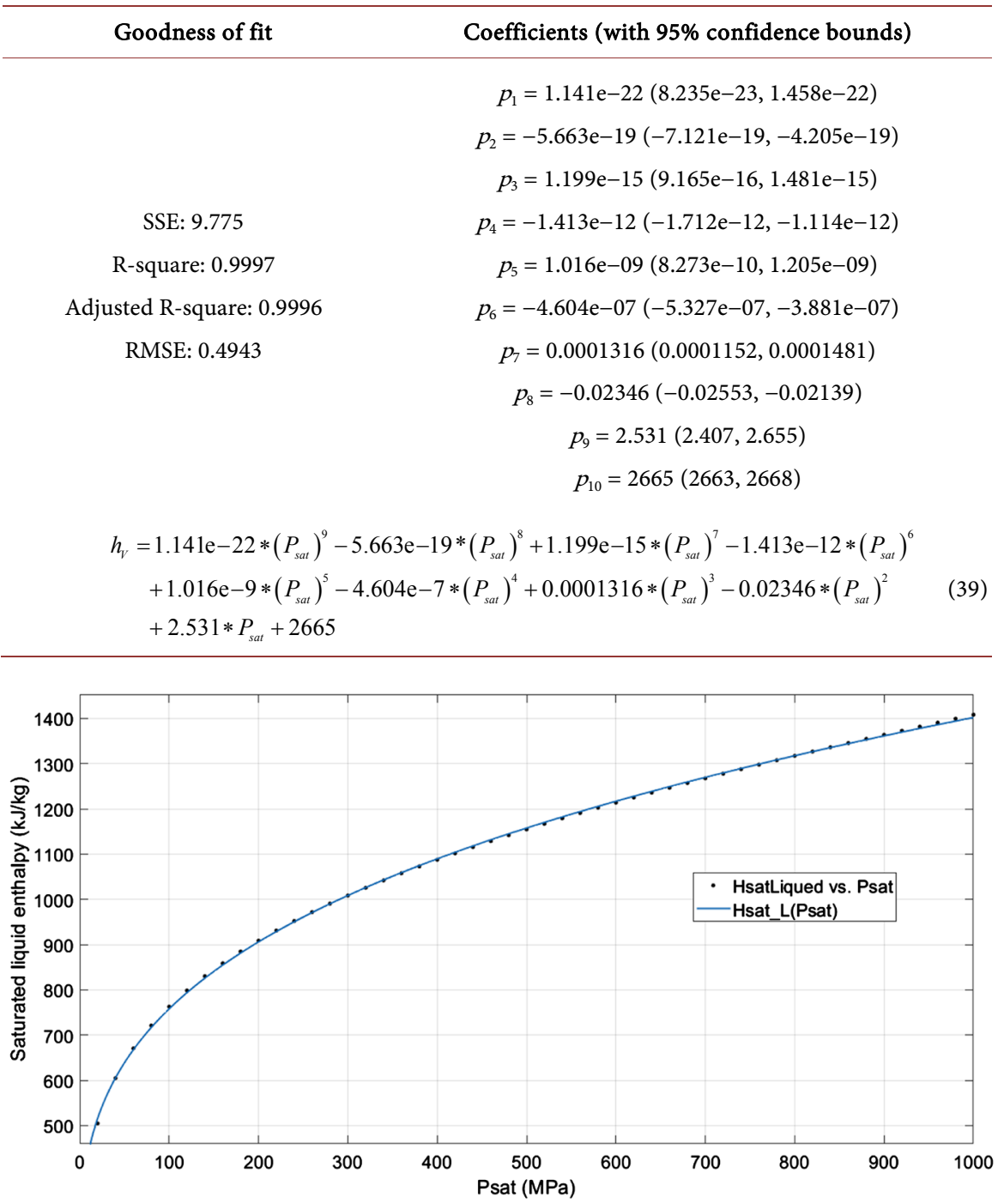

Figure 6. Fitting of saturated liquid enthalpy in terms of $P_{\text {sat }}$ 
Table 7. (a) General form of fitted curve of Saturated Liquid Enthalpy in terms of $P_{\text {sat }}$ (b) Coefficients of the equation with confidence Interval. (c) Goodness of fit.

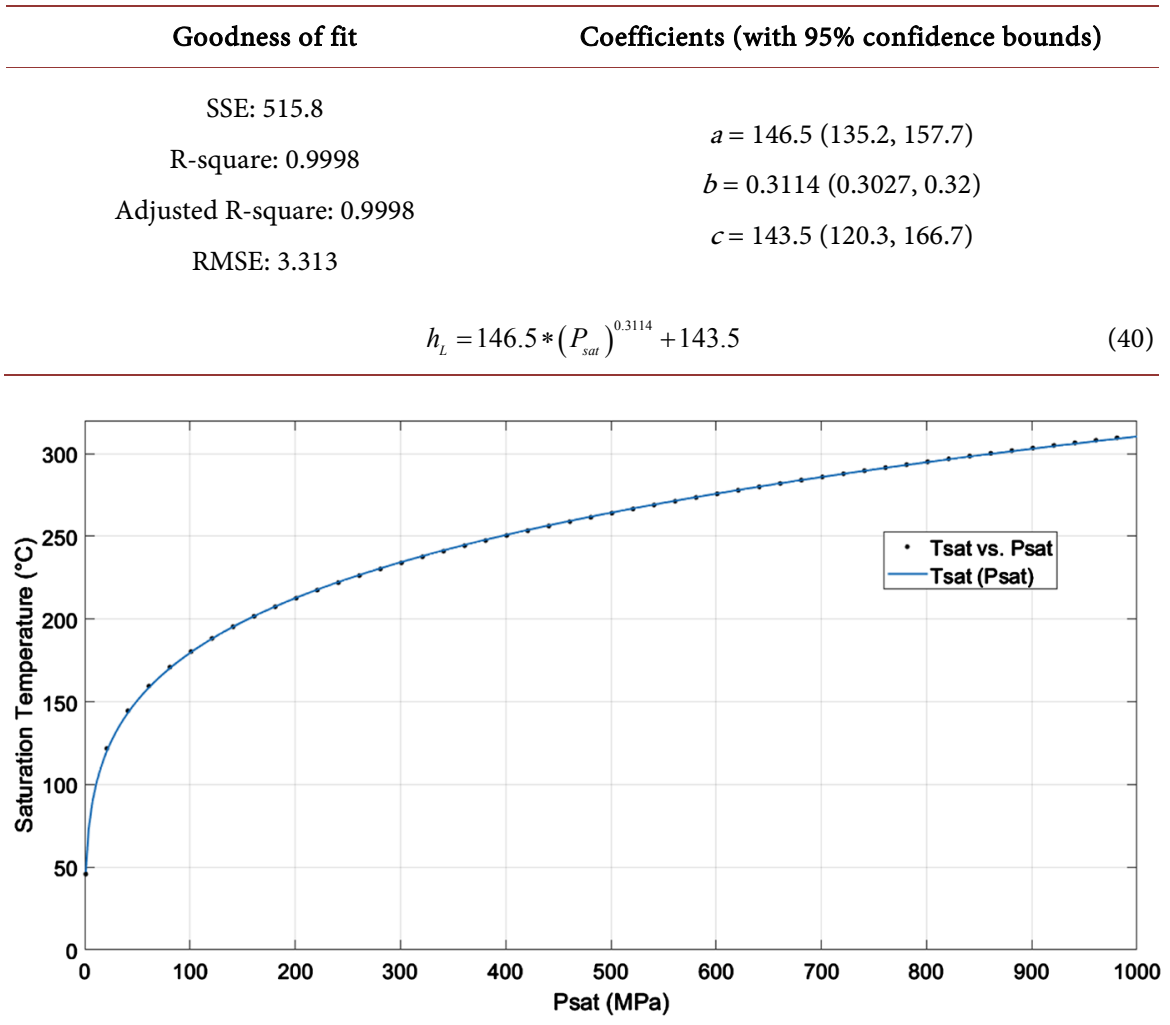

Figure 7. Fitting of saturated temperature in terms of $P_{\text {sat }}$

Table 8. (a) General form of fitted curve of Saturated Temperature in terms of $P_{\text {sao }}$ (b) Coefficients of the equation with confidence Interval. (c) Goodness of fit.

\begin{tabular}{cc}
\hline Goodness of fit & Coefficients (with 95\% confidence bounds) \\
\hline SSE: 11.73 & $a=84.17(81.84,86.51)$ \\
R-square: 0.9999 & $b=0.2052(0.2025,0.208)$ \\
Adjusted R-square: 0.9999 & $c=-37.1(-40.27,-33.93)$ \\
RMSE: 0.4997 & \\
& $T_{\text {sat }}=84.17 *\left(P_{\text {sat }}\right)^{0.2052}-37.1$
\end{tabular}

one, which indicates better fit to the data, and finally, the RMSE, which expresses the standard deviation.

\section{State Variables of UTSG}

The above Equations ((4), (5), (8), (9), (22), (23), (26)-(28)) define the following main UTSG variables:

- $T_{1}$ : temperature of the upward direction primary coolant in inverted U-Tube.

- $T_{2}$ : temperature of the downward direction primary coolant in inverted U-Tube.

- $T_{3}$ : temperature of the metal tube containing upward direction primary wa- 
ter.

- $T_{4}$ : temperature of the metal tube containing downward direction primary water.

- $T_{5}$ : recirculated water temperature before mixing.

- $T_{6}$ : annular tank temperature.

- $L_{d w}$ : water level of recirculated water plus feedwater (mixing region).

- $x$ : steam quality at the exit.

- $P_{\text {sat }}$ secondary coolant saturation pressure.

Now we can arrange these equations in matrix form to be suitable for MATLAB as the following:

$$
\frac{\mathrm{d} X}{\mathrm{~d} t}=A * X+B
$$

and state vector is:

$$
X=\left[\begin{array}{c}
T_{1} \\
T_{2} \\
T_{3} \\
T_{4} \\
T_{5} \\
T_{6} \\
L_{d w} \\
x \\
P_{s a t}
\end{array}\right]
$$

and state matrix is:

$$
\begin{gathered}
A=\left[\begin{array}{ccccccccc}
A_{1,1} & 0 & A_{1,3} & 0 & 0 & 0 & 0 & 0 & 0 \\
A_{2,1} & A_{2,2} & 0 & A_{2,4} & 0 & 0 & 0 & 0 & 0 \\
A_{3,1} & 0 & A_{3,3} & 0 & 0 & 0 & 0 & 0 & 0 \\
0 & A_{4,2} & 0 & A_{4,4} & 0 & 0 & 0 & 0 & 0 \\
0 & 0 & 0 & 0 & A_{5,5} & 0 & 0 & 0 & 0 \\
0 & 0 & 0 & 0 & A_{6,5} & A_{6,6} & 0 & 0 & 0 \\
0 & 0 & 0 & 0 & 0 & 0 & A_{7,7} & 0 & 0 \\
0 & 0 & A_{8,3} & A_{8,4} & A_{8,5} & A_{8,6} & 0 & 0 & 0 \\
0 & 0 & A_{9,3} & A_{9,4} & A_{9,5} & A_{9,6} & 0 & 0 & 0
\end{array}\right] \\
\\
{\left[\begin{array}{c}
B \\
B_{1} \\
0 \\
B_{3} \\
B_{4} \\
B_{5} \\
0 \\
B_{7} \\
B_{8} \\
B_{9}
\end{array}\right]}
\end{gathered}
$$


To make the model works independently, the model must be maintained in a closed-loop situation. This is done by adding the following two control conditions:

1) The flow rate of the exit steam is equal to the flow rate of thefeedwater ( $W_{s o}$ $\left.=W_{f i}\right)$.

2) The flow rate of the exit steam is proportional to the saturated pressure of the steam $\left(W_{s o} / P_{\text {sat }}=\right.$ constant $)$.

Now, by solving Equation (42), and taking into consideration the two control conditions, the UTSG model is presented. It was totally implemented in MATLAB environment. In the next section, some results of running the model in both steady state and transient state will be presented.

\section{Results}

Simulations are carried out by running the MATLAB model for 3 hours (1800 $\mathrm{sec}$ ). Simulations are programmed on a personal computer (Intel Core $\mathrm{C}^{\mathrm{Tm}}$ i5-11600T Processor (12M Cache, up to $4.10 \mathrm{GHz})$ ). The first step is using the initial design data from Table 2 to simulate the steady-state condition. Figures 8-11 show the steady state simulation of the thermodynamic properties $T_{1}, T_{2}$, $T_{3}, T_{4}, P_{\text {sat }}$ and $x$, respectively.

Simulation of the transient performance of the UTSG is also done. As shown in Figure 12, the transient case increases the steam flow by $5 \%$ starting from initial time $t_{i}=500$ seconds tell final time $t_{\mathrm{f}}=1500$ seconds. Figure 13 through Figure 16 show the transient state simulation of the response of thermodynamic properties $T_{1}, T_{2}, T_{3}, T_{4}, P_{\text {sat }}$ and $x$. respectively.

\section{Conclusion}

An accurate mathematical modeling of the U-Tube steam generator, which is introduced in this work, offers a good start to assist a complete simulation for

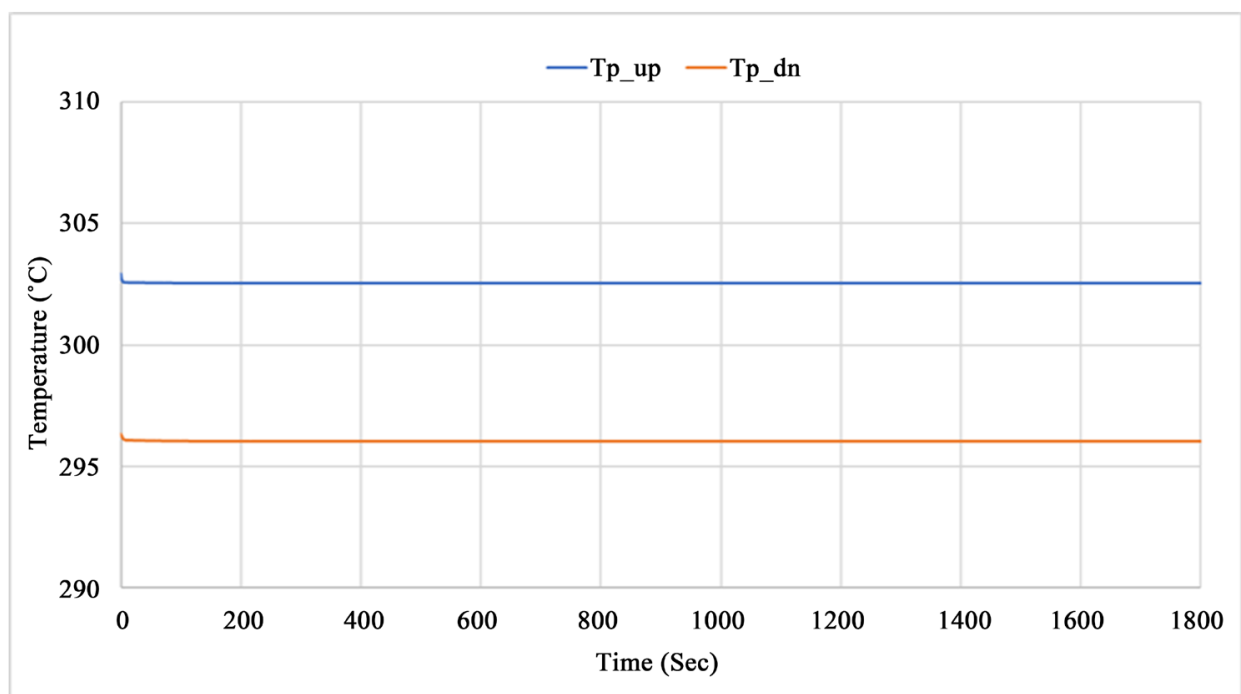

Figure 8. The Tp-up (Tp-dn) inside the U-tube in steady state. 


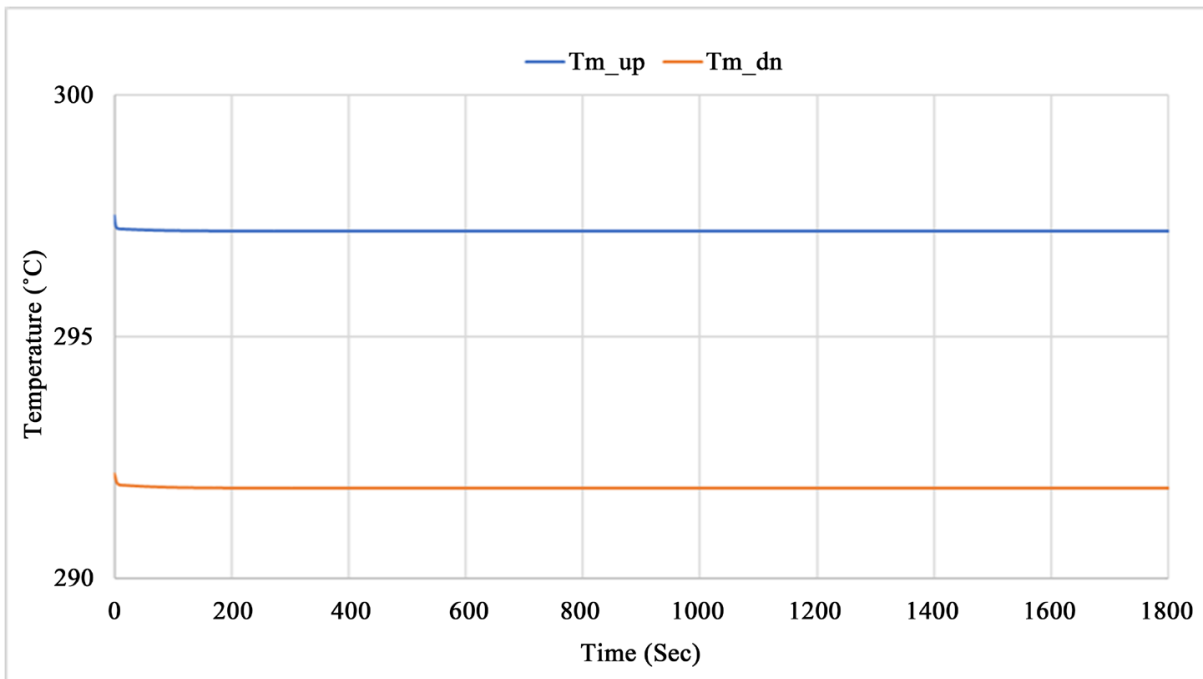

Figure 9. The Tm-up (Tm-dn) inside the U-tube in the steady state.

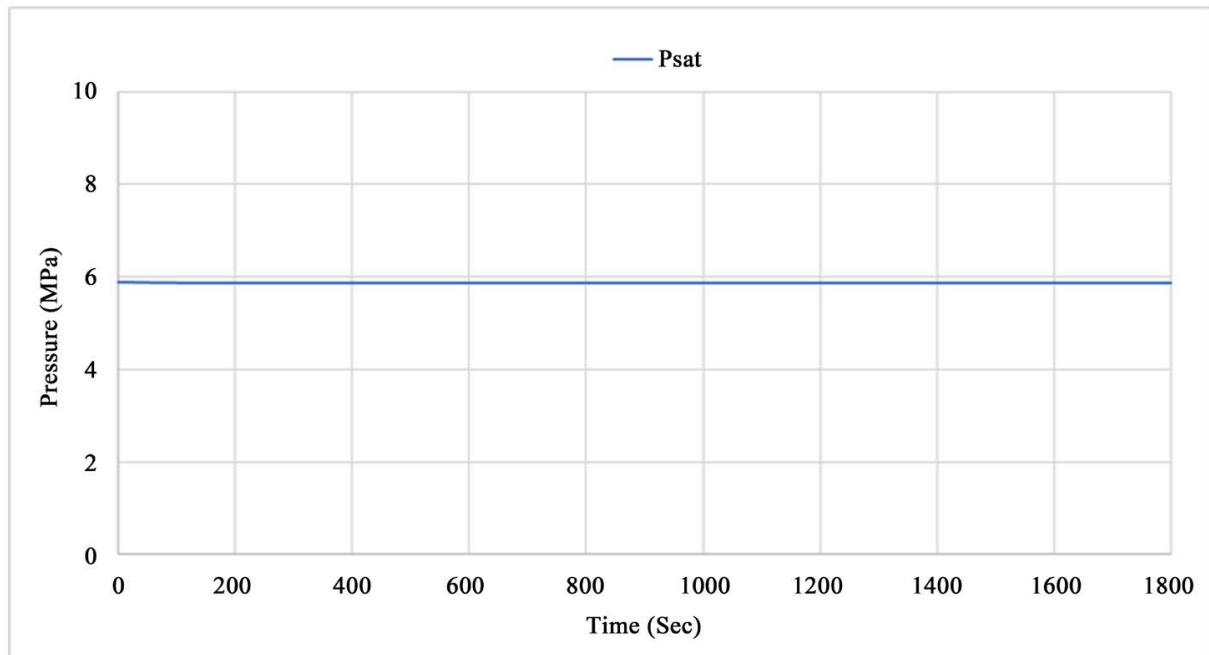

Figure 10. The Psat, in steady state.

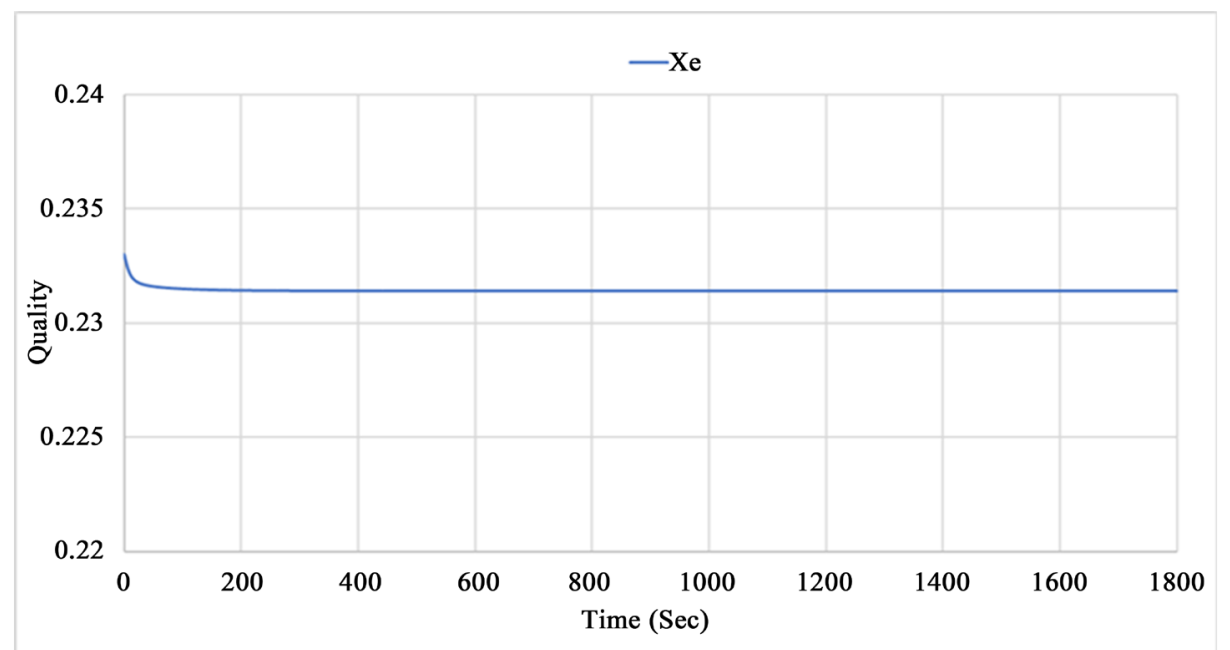

Figure 11. The Xe, in steady state. 


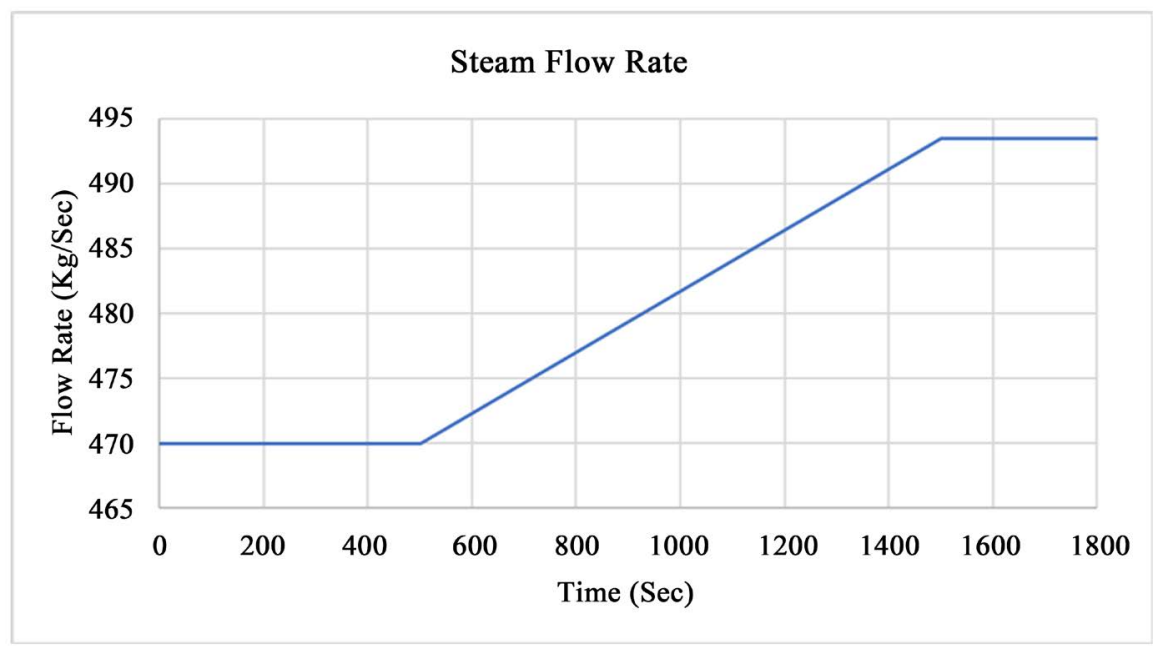

Figure 12. The steam flow rate.

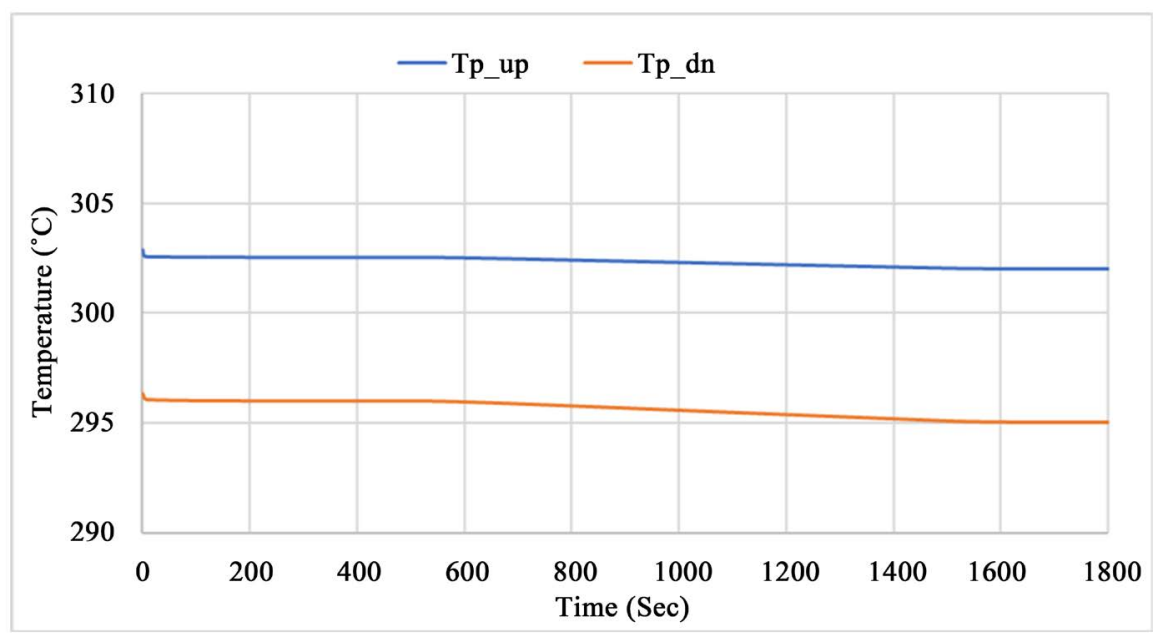

Figure 13. The Tp-up (Tp-dn) inside the U-tube in Steam Flow Increase 5\%.

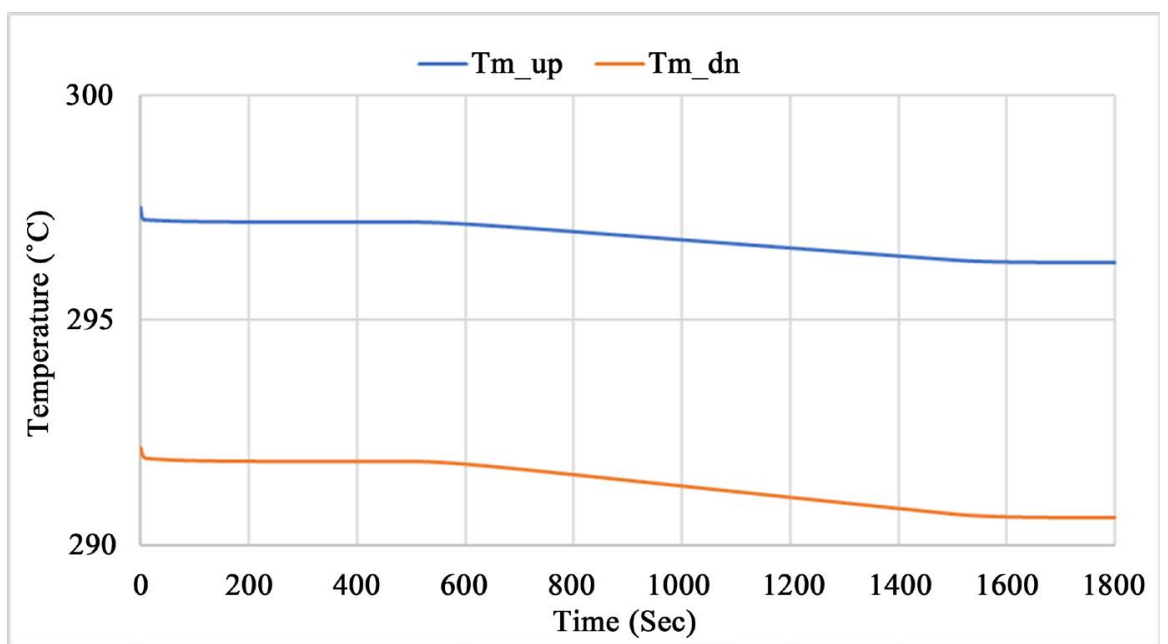

Figure 14. The Tm-up (Tm-dn) inside the U-tube in Steam Flow Increase 5\%. 


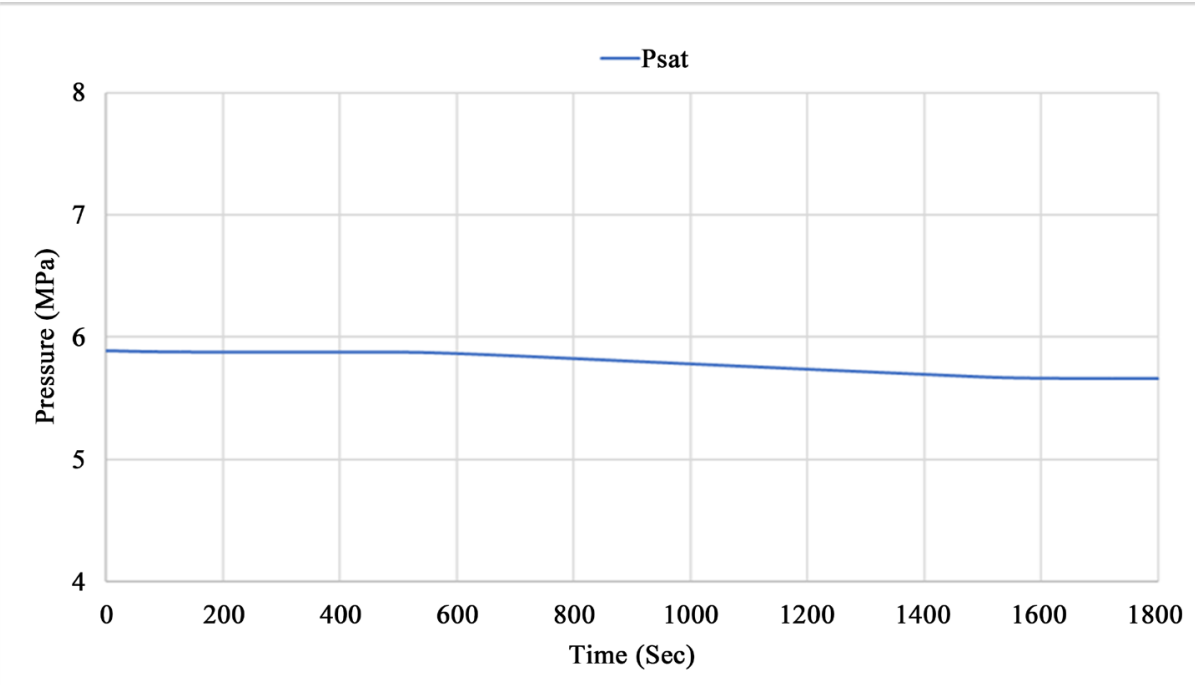

Figure 15. The Psat, in steam flow increase 5\%.

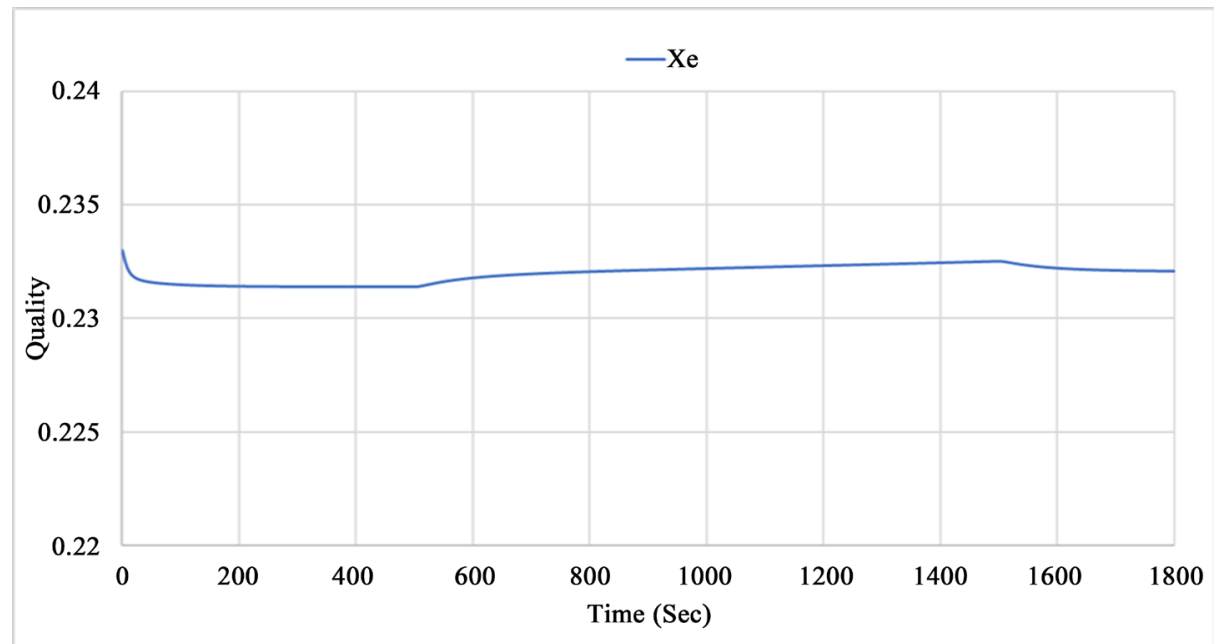

Figure 16. The Xe, in steam flow increase $5 \%$.

the pressurized water reactor. The main advantage of using such highly precision expressions for deducing the thermodynamic relationships is the reduction in the simulation time as these functions provide a very fast calculation and control the safety usage of the PWR. This is because the properties of the vapor are called millions of times within the framework of the model while running and used the interpolation technique with the steam tables. The evidence of the high precision is shown through the statistical quantities computed in the fitting process with $\mathrm{R}$-square being less than 1 in all cases, and can be easily used on their own or through their derivatives or integrals. These computed functions increase the precision for the calculation of the thermodynamic properties of steam/water. Moreover, this model was tested with both static persistence and $5 \%$ transient changes and gave typical and reasonable results that reflect the dynamic characteristics of the steam generator in real time. It shows a good adaptability in a wide range of industrial control. 


\section{Conflicts of Interest}

The authors declare no conflicts of interest regarding the publication of this paper.

\section{References}

[1] Riznic, J. (2017) Introduction to Steam Generators from Heron of Alexandria to Nuclear Power Plants. In: Steam Generators for Nuclear Power Plants, Woodhead Publishing, Cambridge", 3-33. https://doi.org/10.1016/B978-0-08-100894-2.00001-7

[2] Nikolov, A., Pasheva, V. and Gerova, G. (2021) A Simulator of Vertical U-Tube Steam Generator in SCILAB Environment. AIP Conference Proceedings, 2333, Article ID: 090031. https://doi.org/10.1063/5.0041750

[3] Gerova, G. and Pasheva, V. (2017) A Simplified Mathematical Model of Vertical U-Tube Steam Generator in MATLAB Environment. AIP Conference Proceedings, 1910, Article ID: 020016. https://doi.org/10.1063/1.5013953

[4] Guimarães, L.N.F., Oliveira, N.S. and Borges, E.M. (2008) Derivation of a Nine Variable Model of a U-Tube Steam Generator Coupled with a Three-Element Controller. Applied Mathematical Modelling, 32, 1027-1043.

https://doi.org/10.1016/j.apm.2007.02.022

[5] Haar, L., Gallagher, J.S. and Kell, G.S. (1984) NBS/NRC Steam Tables Thermodynamic and Transport Properties and Computer Programs for Vapor and Liquid States of Water in SI Units.

[6] Dong, Z., et al. (2009) Dynamic Model for Control System Design and Simulation of a Low Temperature Nuclear Reactor. Nuclear Engineering and Design, 239, 2141-2151. https://doi.org/10.1016/j.nucengdes.2009.05.006

[7] Wan, J., Wu, S., Nuerlan, A. and Zhao, F. (2017) Dynamic Modeling of AP1000 Steam Generator for Control System Design and Simulation. Annals of Nuclear Energy, 109, 648-657. https://doi.org/10.1016/j.anucene.2017.05.016

[8] Ahmed, A.S.E., Elhosseini, M.A. and Arafat Ali, H. (2018) Modelling and Practical Studying of Heat Recovery Steam Generator (HRSG) Drum Dynamics and Approach Point Effect on Control Valves. Ain Shams Engineering Journal, 9, 3187-3196. https://doi.org/10.1016/j.asej.2018.06.004

[9] Li, X., Xu, E., Ma, L., Song, S. and Xu, L. (2019) Modeling and Dynamic Simulation of a Steam Generation System for a Parabolic Trough Solar Power Plant. Renewable Energy, 132, 998-1017. https://doi.org/10.1016/j.renene.2018.06.094

[10] Dong, Z. and Pan, Y. (2018) A Lumped-Parameter Dynamical Model of a Nuclear Heating Reactor Cogeneration Plant. Energy, 145, 638-656. https://doi.org/10.1016/j.energy.2017.12.153

[11] Sohn, J.J. and Seong, P.H. (2010) A Steam Generator Model Identification and Robust $\mathrm{H} \infty$ Controller Design with $v$-Gap Metric for a Feedwater Control System. Annals of Nuclear Energy, 37, 180-195. https://doi.org/10.1016/j.anucene.2009.11.005

[12] Zhang, Y.S. and Ma, Y.Y. (2010) A Simplified Lumped Parameter Model for U-Tube Steam Generator. 2010 International Conference on Electrical and Control Engineering, Wuhan, 25-27 June 2010, 253-256. https://doi.org/10.1109/iCECE.2010.68

[13] Ordys, A.W., Pike, A.W., Johnson, M.A., Katebi, R.M. and Grimble, M.J. (1994) Process Models. In: Modelling and Simulation of Power Generation Plants, Sprin- 
ger, London, 117-215. https://doi.org/10.1007/978-1-4471-2114-5_4

[14] Ali, M.R.A. (1976) Lumped Parameter, State Variable Dynamic Models for U-Tube Recirculation Type Nuclear Steam Generator. PhD Dissertation, The University of Tennessee, Knoxville.

[15] Kolev, N.I. (2015) Multiphase Flow Dynamics 5. Springer International Publishing, Berlin. https://doi.org/10.1007/978-3-319-15156-4

[16] Release on the IAPWS Formulation 2011 for the Thermal Conductivity of Ordinary Water Substance, September 2011. http://www.iapws.org/relguide/ThCond.html 